\title{
Electrical Energy Engineering Education for 21st Century
}

\section{Dr. Radian G Belu, Southern University and A\&M College}

Dr. Radian Belu is Associate Professor within Electrical Engineering Department, Southern University, Baton, Rouge, USA. He is holding one PHD in power engineering and other one in physics. Before joining to Southern University Dr. Belu hold faculty, research and industry positions at universities and research institutes in Romania, Canada and United States. He also worked for several years in industry as project manager, senior engineer and consultant. He has taught and developed undergraduate and graduate courses in power electronics, power systems, renewable energy, smart grids, control, electric machines, instrumentation, radar and remote sensing, numerical methods, space and atmosphere physics, and applied physics. His research interests included power system stability, control and protection, renewable energy system analysis, assessment and design, smart microgrids, power electronics and electric machines for non-conventional energy conversion, remote sensing, wave and turbulence, numerical modeling, electromagnetic compatibility and engineering education. During his career Dr. Belu published ten book chapters, several papers in referred journals and in conference proceedings in his areas of the research interests. He has also been PI or Co-PI for various research projects United States and abroad in power systems analysis and protection, load and energy demand forecasting, renewable energy, microgrids, wave and turbulence, radar and remote sensing, instrumentation, atmosphere physics, electromagnetic compatibility, and engineering education.

\section{Prof. Lucian Ionel Cioca, Lucian Blaga University of Sibiu}

Lucian Ionel CIOCA received the M.Sc. in Machine Tools (1993) and B.Sc. in Occupational Safety, Health and Work Relations Management (2010). In 2002, he becomes Dr. Eng. (Ph.D degree) of Petrosani University, Romania and now he is professor at "Lucian Blaga" University of Sibiu - Romania, Faculty of Engineering, Department of Industrial Engineering and Management, Romania. His teaching subjects are Ergonomics, Management, Human Resources Management, Occupational Health and Safety Management, Production Systems Engineering. His research fields of interest are linked with the impact of the knowledge based society upon the social / human dynamics / evolution and the production systems. He regularly publishes and participates on international scientific conferences. Lucian Cioca is the Administrator of the LBUS Department of Consulting, Training and Lifelong Learning, Doctoral Advisor in Engineering and Management, Member of the National Council for Attestation of Academic Titles, Diplomas and Certificates, evaluator ARACIS (The Romanian Agency for Quality Assurance in Higher Education), and other (email: lucian.cioca@ulbsibiu). 


\section{Electrical Energy Engineering Education for $21^{\text {st }}$ Century}

\section{Introduction}

Unprecedented technological and scientific advances in power and energy engineering presents interesting challenges and opportunities for professionals, research and engineering educators alike. Electrical energy industry is the cornerstone of a prosperous society, all critical socioeconomic functions depending on the secure and reliable power and energy infrastructures. Due to the increased complexity and technology advancements in all power and energy industry sectors (generation, transmission, distribution, control, protection, costumer participation, economics, etc.), there are growing needs for graduates to be specialized in power and energy engineering. Electrical energy and power engineering education has undergone significant changes over the last two decades, together with an increased student interests into such engineering programs. Power and electrical energy engineering programs have been revived in many universities in the U.S. and in other countries. Today, with the renewed interests and support from industries and governments, energy engineering programs are being rebuilt with a strong interdisciplinary curricula fueled mainly by the industry needs. Moreover, recent changes into the power and electrical energy industrial and manufacturing sectors, restructuring the utilities, smart grid, and low-carbon economy require graduates with a broader understanding of technology, economics, social contexts and skills [1-5]. There are growing recognition of the needs to improve, restructure and reform electrical energy and power engineering curricula. The issues surrounding this theme are receiving significant interests form faculty, industry professionals and often administration. Electrical energy professionals are required to have significant scientific capabilities, deep interdisciplinary understandings, and soft skills, e.g. selflearning abilities, communication or interpersonal competence. However, how and which are the best approaches to better educate the next generation of power engineers, remain an open question. The fresh graduates need enhanced knowledge and skills in leadership, communication, data analysis, management, economics, in addition to those in engineering, mathematics, physics, circuit analysis, energy conversion, signals and systems, which are the pillars of engineering education [4-16]. The requirements for such skills and knowledge are in large part a consequence of the evolution and changes into electrical energy systems, from the centralized grid structure, generation and control with unidirectional power flows to a new structure, the smart grid, in which significant distributed generation is located at transmission and distribution levels. In addition of teaching traditional power engineering courses, new courses and topics must be included into curriculum, such as renewable energy, advanced power electronics, smart grids, energy management, to mention a few of them while still ensuring a four-year graduation timeframe. There are also increased demands for continuous education of the professionals, engineers and technicians in these emerging energy technological areas. A well-designed power engineering curriculum must offer a judicious balance between the basic sciences, strong electrical engineering foundations, laboratory and hands-on experience, design work, communication skills, management, economics and humanities. This paper is proposing to discuss some of the energy engineering education challenges, issues and opportunities.

\section{Power and Energy Engineering Trends, Challenges and Opportunities}

The modern power system has changed significantly from the very modest beginnings to very complex and large systems, which are perhaps the largest enterprise ever built by humans. Mo 
Power systems are facing structural changes including among others, market liberalization, integration of renewable energy sources and customer participation. The power system and its wiring connect nowadays every single house to each other and to the power stations together within a country or region. Furthermore, states and countries are inter-connected together so that whole continents are joined together to enable smooth, secure and economical production and transfer of electric energy. This huge system needs very efficient automation, management and control systems with real-time communication connections over long distances. In the same time, the unprecedented economy globalization has amplified the impacts of technology and science discoveries on the modern societies in ways that have not been predicted. The connectivity provided by the internet and communication technologies has generated new products, services, business market opportunities, making in the same time available workforce that is often welleducated and cheap. This is likely to have profound impacts on the wealth distribution in developed and developing countries, and changes into the socio-economic structure of countries where the population general wellbeing has been taken for granted. Modern energy industries are going through an evolutionary period and these new technologies are changing the way the electricity is generated, transmitted, delivered and used. The power and energy industries have many new applications in the forefront. The essential roles that education and research are playing into any nation prosperity is not debated, but there are arguments that how specifically the presence of knowledge and know-how that determines how well-off the societies are.

Environmental concerns, the demands for higher and higher power generation, and steady progress in electricity market deregulation have created interests in environmentally conscious distributed power generation and renewable energy sources. Of particular interest are renewable energy sources such as wind, solar energy systems, fuel cells and distributed generation devices with near zero emissions of hazardous pollutants. These generation systems can be used in standalone configurations, microgrids or in configuration connected to the power networks for grid reinforcement. Given the rapid progress in alternative energy and distributed generation technologies and usage, there is a greater need for trained professionals and engineers with adequate knowledge in these areas to be able to plan, design and operate such systems, and perform analytic evaluation of their impact on power systems to which they are connected. The integration of intermittent energy sources in the power system creates manifold challenges and problems, which have not been overcome yet. Breakthroughs in system design, transfer and energy storage technologies, as well as economic organization are needed. The renewable energy generation nature contradicts the conventional power system structure with large centralized power plants. On the one hand, decentralized generation suggests shifting to small-scale systems, whereas the intermittent generation nature favors large-scale systems. However, there are several advantages of the small-scale systems that should lead to research efforts in several directions, e.g. microgrids, a promising approach for increasing the supply autonomy and security. Microgrids require new control architectures requesting research into that direction. Another highly important technology that requires research is decentralized energy storage. A major goal of research on energy storage should lie in trying to achieve cost reductions. While technologies set limits for arbitrarily high renewable energy shares, the regulatory framework and individual incentives are already allowing increasing the use of photovoltaics and decentralized energy storage. However, the major challenges are thus not only technology driven. 
It is worth to notice that a widely accepted new fundamental power system design does not exist yet. Discussions are largely limited to individual proposals and demonstrations. The path which will finally be chosen is not obvious at the moment. However, the U.S. Energy Independence and Security Act of 2007 [2] indicated that it is the U.S. policy to support the modernization of the transmission and distribution system to maintain a reliable and secure electricity infrastructure to meet further demand growth and achieve the following characteristics and functionalities: 1) Increased use of digital information and controls technology to improve reliability, security, and efficiency of the electric grid; 2) Dynamic optimization of grid operations and resources, with full cyber-security; 3) Deployment and integration of distributed generation, including renewable energy; 4) Development and incorporation of demand response, demand-side and energyefficiency resources; 5) Deployment of smart technologies for metering, power grid communications, and distribution automation; 6) Integration of smart appliances and consumer devices; 7) Deployment and integration of advanced electricity storage and peak-shaving technologies; 8) Provision to consumers of timely information and control options; 9) Development of standards for communication and interoperability of appliances and equipment connected to the electric grid; and 10) Identification and lowering of unreasonable or unnecessary barriers to adoption of smart grid technologies, practices, and services. During the last decades a major change has happened in the way electricity market is running. Earlier it was a monopoly where only few, usually state or municipality owned companies, were running the business, energy market being now deregulated and privatized. In addition to the energy business the second important area where power engineering skills are needed is industrial production. Power systems have a large variety of components, generators, transformers, cables, relays and substations. In addition, the electricity end-use may require high power equipment e.g. power supplies, frequency converters and several types of electric machines. Their design and manufacturing offers scores of jobs for power engineers and technicians. Industry in this area is very international and typically it exports a large part of the products. Further, certain companies, manufacturers, suppliers, consultants that have not traditionally been engaged in the electric power and energy industries are finding new markets in this growing and dynamic space. Through the revolutionary changes occurring in the electric power, new products, technologies, and skills are needed and are finding their way into the smart grid. The potential is tremendous, whether in the areas of communications, devices, or advanced products, or applied knowledge; they can gain great value from employee training through such a modernized program.

Power quality is another rapidly evolving field within power engineering involving the analysis, modeling, and mitigation of the difficulties related to voltage and current distortions, protection and related issues in power systems. This area also are requiring a suitable workforce, trained professionals and engineers able to conduct and perform research, operate and manage power systems, and to ensure power quality as required and prescribed by standards and codes. Most of the potential effects, form power quality on the power grid are from power electronic systems and nonlinear loads, e.g. harmonics, voltage variations, transients, are power quality events. Power quality is also increasingly important for the users, customer side, because there are increased uses of the sensitivity loads and microprocessor-based equipment, affected by even minor electricity power quality events. Power quality touches many areas relevant to energy and power systems: applied mathematics, energy management, power electronics, economic analysis, reliability, and power distribution systems among others. Thus, the multidisciplinary nature of power quality presents an opportunity to integrate various aspects of energy and power systems 
research. The power quality research and related-education activities are prepare a new kind of power engineer, able to meet the energy challenges of the 21st century. Power quality are linking power systems, power electronics and contemporary energy and power issues in order to create an integrated perspective of today energy and power systems. Current research plans are centered on the power quality impact of integrating alternate energy sources to the power distribution systems. The educational aspect can provide alternatives for a renovation of energy education by implementing power quality activities in the power engineering curriculum [12-36].

The education of engineers and the existence of a well-prepared technical workforce are therefore critical to every nation to ensure the prosperity of their citizens. Engineers and scientists have always learned and tried to tackle new challenges or to find solutions of the problems. However, the unprecedented availability of tools, computers and equipment to do almost everything does, however, suggest that engineering educators must rethink how students are prepared and educated in their disciplines. Computer programs and software packages to do virtually anything, from simple calculations, to simulating complex systems, to design a complete engineered system, are empowering the engineers and students, alike to do more than his or her predecessors could ever imagine. These tools and equipment are requiring not only that an engineer knows how to use them, but they are also requiring him or her to be able to assess what tool is appropriate for a given task and then to be able to evaluate the result in critical ways. While teaching students on the fundamentals of the applied sciences is at the core of modern engineering education, re-examining how the fundamentals of engineering sciences are taught to students is needed and is a must. Knowing the scale of phenomena and the distribution of knowledge over multi-scales are critical and essential attributes. In addition to these changes into the technical skills and fundamental knowledge engineers must possess, their non-technical professional skills must be suited for the modern way of doing engineering and to the modern engineering business. One of the drivers for power engineering education at the graduate level is the pertinence and excitement of research projects. However, the long term research work on more difficult topics tends to be more motivational for graduate students and to encourage undergraduate students to pursue graduate studies in power and energy engineering. A full list of grand challenges is too expensive to produce, but a sampling below illustrates the types of material that excite and may serve to recruit) students. Among the new attractive research power and energy areas are: conducting research to effectively develop and design commercial superconductivity applications in underground transmission, solving the greatest problems of power electronics, the increase junction voltages well beyond the $\mathrm{kV}$ levels, applications of the smart advanced sensors and information processing technology in the future smart grid operation and management, smart microgrid protection and control, or robust grid integration of renewable energy systems, DC nanogrids, and DC power distribution protection and control [16-38].

\section{Power and Energy Engineering Education Status and Challenges}

Over the years, engineering curricula across the United States and in many other countries have undergone rather substantial changes. Today, traditional curriculum needs for engineers that seek specialization in electric power or energy areas have been well defined and fairly stable over the last few decades. This seems quite logical, as the engineering profession has itself undergone significant changes, driven primarily by technological developments, economic and societal needs. But in recent years, not all changes in the engineering curricula have mirrored changes in 
the profession or industries. In fact, some changes have worked in opposition to meeting industry's needs of the education system by narrowing the scope of education while industry wants more breadth [12-36]. Due to the pressure to reduce the credit hour requirement of the baccalaureate degree, almost all U.S. electrical engineering programs have reduced their credit hour requirements over the past decade. Most of the BSEE programs required over 150 credits until 1980, 136 semester credits before 2000, and 1about 28 credits from 2001 [24-42]. Similar trends can be found at many other countries universities. Designing a model curriculum for power and energy engineering consisted with the industry needs, must assess how effectively the existing curriculum meets industry needs, then identifying the specific enhancements to the existing curriculum to align better the academic programs to the industry expectations. However, the existing engineering curricula are still giving the impression that power and energy systems, control theory and power electronics on one hand and computing, information technology and communication networks on the other, are continuing to evolve in parallel tracks. The myths are that the application space is irrelevant in the study of communication and computer networks, and that control techniques, power electronics and power system applications are using the communications and computations as commodities. Noticing that, grid and power system operations are vitally dependent on sharing data, information and communication, and must be reflected into our courses and into non direct related power engineering course contents. Power and energy engineering have now commoditized the network and computation solutions, finding the off-the-shelves products that are fitting the day needs, by defining a logical mapping between desired functions, capabilities and communications standards.

Teaching and research in electrical power engineering has a long history as one of the first electrical engineering field. Power and energy engineering is still the cornerstone of the modern society, e.g. efficient generation, transfer, distribution and the use of electricity. The peculiar electricity nature is that it is very difficult to store it in large quantities, which would have energetic importance. Therefore, from the very beginning efficient and secure power distribution has been a key element in the development of societies. The workforce demand in the electrical power industry is also evolving in agreement with the significant changes and evolutions into the technology and industry. In order to be a successful proficient power and energy engineer in the $21^{\text {st }}$ century, one must have multiple skills in cross disciplinary areas. The industry is demanding power engineering education to broaden in a cross function of areas such as networking, control systems, power electronics, energy management, data analytics along with information security and business, contributing to match the technical engineering ingenuity with the dynamics of the smart grid and energy infrastructure [21-42]. The smart grid has many obstacles to overcome, such as, pricing structure, agreement on information protocol, continuing standardization, development of low-cost smart appliances and numerous commercial issues. Traditional the electric power engineering mainly consists of the following conceptual areas: Traditional power generation; Transmission and distribution; AC circuits, including three-phase theory; Electric machinery; Modern concepts in generation, fuel utilization, sustainability, and the environment; Power systems engineering; Power quality; Power protection; and Power electronics.

For various reasons, these engineering areas tend to attract a limited, modest attention in most undergraduate engineering programs. On the other hand, undergraduate students themselves are often unsure of their areas of interests, being a quite clear impression, among many educators and faculty that power and energy engineering programs continue to capture a lower percentage 
of the undergraduate engineering students. Recent or older published data are estimating that about $10 \%$ or even lower percentage of all electrical engineering students in the USA are in the power and energy engineering programs at universities and colleges that are offering power and energy engineering electives, minors or programs. In UE, Japan, India and China, some of the EE programs are more traditional structured, and the power and energy engineering areas have higher enrollments, but not significantly higher. However, there are few particularly brighter areas into the undergraduate and graduate power engineering education picture. Many universities now have active power and energy engineering programs in which local and regional industry, utilities and corporations participates with the university to support graduate and undergraduate students, while industry-relevant topics are brought to the campus, and hiring programs are in effect. National Science Foundation and the Electric Power Research Institute continue to support research programs for power and energy engineering. Some of these funds form an important part of university research and educational infrastructure budgets in power and energy engineering. This program impacts not only U.S. programs but also international students who populate these programs. Encouragingly industry and academia are in close agreement on the key issues and what needs to be done. The universities welcome closer collaboration with industry, ensuring that the graduates can apply their knowledge effectively in real engineering settings, the opportunity to develop and implement new courses and programs. It is essential that we provide the right conditions in university engineering departments for such university/industry partnerships, as well as new approaches to learning and teaching, to flourish.

\section{Our New Power and Energy Engineering Minor}

Electrical engineering problems are complex, being even truer in power and energy engineering, with the dynamic behavior of the gri and a large number of components and states. It is difficult for the teacher, who is limited to verbal description and static pictures, to explain complicated materials e.g. complex parameter dependencies or, as often encountered in electric machines, power system analysis, renewable energy conversion or for example in power electronics circuitry, where current conduction which is dependent on switching states. Restructuring and reshaping of the electric power systems, in the context of smart grid paradigm and the rapid drive towards the integration of distributed generation and renewable energy systems have highlighted also the needs for power system education for non-engineers. During the 2017-2018 academic year, we proposed, the department and the college curriculum committees approved to establish a minor in power and energy engineering. This initiative was strongly supported by the industrial advisory board and by our major industry sponsors, e.g. Entergy. Major challenges faced with this project are the lack of adequate laboratory facilities, software licenses, properly trained teaching assistants and longer time since such power engineering courses were offered [36-48]. We have also have to keep in mind that an upgrading of a power engineering laboratory is an expensive enterprise and requires adequate laboratory facility, space and support. Recent power industry developments demonstrate that technical understanding of power systems, underscored by hands-on laboratory experience, is even more important than some might have previously thought. A versatile laboratory, providing coverage separately or in combination, became a valuable asset, which can be used for various experiments, while emphasizing on different facets of power systems analysis, power electronics and control, machine characteristics or energy conversion concepts. While most of the laboratory can support the energy conversion, the addition of power electronics and control modules, integrated with what is already in place, would vastly increase the laboratory versatility, functionality, and pedagogical values. To 
address these needs, we are designing our power engineering facility in an integrated and modular structure. Combining energy conversion, power systems, renewable energy, power electronics and control experiments in a versatile integrated laboratory is our current goals. Other questions we are addressing are how to improve and update the existing courses, what are the cortical topics needed to be included, what new courses are important and need to be developed, and which are the courses that need to include projects or mini-projects, what is the most appropriate teaching methodology for each of the courses, and to what extent course materials must be covered. In our views all are critical questions that must be answered and handled properly in order to establish a strong and modern power engineering concentration. It is wellaccepted that the educational requirements of a power engineering program or concentration need to be shaped, not only by the academic requirements but also by the industries who are hiring the graduates [24-42]. Doing so is the best means of assuring that our graduates have the skills necessary to succeed in their future workplace, e.g. proficient in engineering, having good communication and management skills, and being able to be successful with minimum supervision is a necessity, as there are quite often minimal resources in the form of experienced engineers to help train the new engineers. We had these in minds when we started to restructure and upgrade the existing courses, propose and develop new courses.

Electric Machines I: This 3-credit course is designed to provide foundations in the operation, principles, construction, performances and testing of major electrical machines, being offered once a year usually during the spring semester. Topics covered are the fundamentals of magnetic circuits, transformers and rotating electric machinery, both DC and AC machinery. In addition to that, we are also included comprehensive discussions of the control methods, techniques and most important applications for each of the major types of electric machines included in this course.

Electric Machines II: This course covers topics in steady state and dynamic characteristics of DC and AC machinery and energy conversion systems, control and protection. This course was offered only a couple of times, and not been offered since Fall 2000 semester. So far no decision was made regarding the status of this course. If the course remains as it is, a stronger emphasizes will be on topics related to the electric machine dynamic analysis, advanced control, design and modeling. Any suggestions and recommendations from audience are highly appreciated.

Power System Analysis: This course introduces student to power systems concepts, per unit concepts and notations, power flow analysis methods, faults, symmetrical components, and symmetrical and unsymmetrical faults on the transmission line.

Power System Design: It covers advanced topics in generation, distribution, and transmission related to power systems, including the synthesis of various design topics is treated. However this course was not offered for a long time. We are planning to change the course content and catalog number to be offered as a combined undergraduate and graduate course. The new course is focusing on power generation, operation and control, the topics include: power system concepts, generation characteristics, energy sources, economic dispatch, unit commitment, generation with limited energy supply, power transmission, power flow analysis, power system security, control of power generation, demand forecasting, and power system economics.

The proposed new courses included into power and energy engineering minor are discussed here: 
Introduction to Energy System Engineering: This course is an introductory subject in electric power systems and energy conversion. Electric power has become increasingly important as a way of transmitting and transforming energy in industry, military and transportation uses, which include also topics related to the electric transportation systems, batteries, fuel cells, energy storage devices, distributed generation and power system applications. Electric power systems are also at the heart of alternative energy systems, wind and solar electric, geothermal and small scale hydroelectric generation. The course is intended for all engineering students, and is offered as sophomore elective, having pre-requisites of certain engineering, math and physics courses.

Power Electronics: All good university power engineering programs include power electronics courses. However, one of the emerging technologies in electrical engineering where a continuous curriculum update is essential is power electronics and its applications. This area needs a basic understanding of electrical engineering fields and a good knowledge of the systems, in which power electronics converters are used. Furthermore, the field is characterized by that practical skills are being important in respect to understanding the system where power electronics is used in and realize it in practice. The course is designed to study of the capabilities and limitations of power semiconductor devices, analysis, design and analysis of common circuit topologies for power conditioning and processing, converters, switch-mode power supplies and applications.

Renewable Energy Systems: It is a four credit-hour integrated lecture-laboratory course, which primarily focuses on wind energy conversion systems, solar-thermal and photovoltaic energy systems, marine energy, energy storage and fuel cells. To a lesser extend it focuses on other renewable energy sources. This course is meant to enable the students to apply basic science knowledge to renewable energy systems. The role of new energy resources, technologies, and the effects of market forces are discussed in details. Grid integration of renewable energy systems and related issues are also presented and discussed, as well as the economic aspects, environmental impacts of alternative energy and social policy are integral course components.

Power Distribution: This course is focusing on electric power distribution system analysis, design and operations, including load estimates and calculation, sub-transmission lines, distribution substations, feeder design considerations, voltage regulation, protection and reliability of power distribution systems. Special topics related to power distribution and advanced metering and monitoring infrastructure, distributed generation and smart grid application are also included. Upon completion of this course, students are able to: analyze and model power distribution system components, to compute the electric performance of a part of the power distribution or a system component, cost-performance analysis, perform a preliminary design of a small part of the distribution system or a system component in order to achieve safe and economic operation, and have a deep understanding of protection issues, faults, symmetrical components, thermal effects of fault currents, the operation of overcurrent protection devices, and the coordination of these devices in order to derive a reliable protection schemes.

Introduction to Smart Grids: The course is intended to provide the students with knowledge of the fundamentals, design, analysis of smart grid (SG) paradigm, offering an introduction to the basic concepts of power systems along with the inherent elements of computational intelligence, communication technology and decision support, automation and computational techniques 
needed to ensure that the smart grid guarantees adaptability and capability of handling new system, components, and interoperability with renewable energy, distributed generation and smart loads. The goals are to give the students good understanding of SG architecture, structure, operation and management. This is a combined undergraduate and graduate course, targeting not only electrical engineering students, but also professionals and students from computer sciences, computer engineering and mechanical engineering, enrolled in dual programs.

\section{A Unified Energy Conversion, Power Electronics, Renewable Energy and Power Engineering Laboratory}

The role of laboratories in modern power engineering education is well accepted and established. Nevertheless laboratories and experimentation are an important part of the engineering curricula and education. In the past, undergraduate electrical power engineering education used the traditional electrical machine and high voltage laboratories. However, fast developments of computers and IT sectors shifted the engineering education, as well as energy engineering education towards the use of computers, simulation and multimedia instead of conventional settings. The main problem of power engineering education is the continuous and very dynamic technology developments. The curricula must adapt to these technological developments and the laboratory education has to follow this trend as well. This suggests that laboratory instruction has even a greater value as a component of power and energy engineering curriculum. During the 2017-2018 academic year an overall inventory and status of electric machines, power electronics and power system equipment and components were conducted, components tested and checked. Additional parts, components, data acquision and power electronics modules, rectifiers, DC-DC convertors, and DC-AC convertors are planned to be purchased, thanks to donations from local industry. Four integrated electric machines and power electronics workstations are functional and are already employed in our integrated laboratory. The energy conversion and power electronics experiments will include: single- and three-phase power measurement, transformers, DC machines, induction and synchronous motors, alternators, single-phase motors, DC-DC converters, rectifiers, inverters and drives. Additional workstations are in process to be set for Fall 2021 semester. A local network of eight desktops and a network workstation will be in operation in the integrated laboratory. For the renewable energy laboratory components, we are planning to replicate the virtual laboratory units and integrated model previously developed by one of the author for other institution. Emulators of major renewable energy systems, wind turbines, Savonius rotor, photovoltaic module, battery bank and a fuel cell stack are designed and will be implemented. Each emulator is an interactive model of the actual renewable energy source, scaled up at the desired level. In addition, an e-Learning support platform for learning renewable energy theory, concepts and experimental procedures are also in process to be designed and implemented [36-42]. The e-Learning support platform is also designed for presential, online or hybrid use. Contacts were also established with local utilities and energy industry for the integrated power and utility laboratory support.

\section{Conclusions}

This paper is giving a brief discussion of the issues, challenges and opportunities offered by power and energy engineering education. In order to face the modern energy issues, research studies are needed on areas such as improved energy utilization, energy policy issues, alternate 
energy sources, distributed generation and the economic impact of deregulation related to reliability concerns. The objective is to maintain a reliable, secure, efficient and economic viable power supply, by addressing any future shortage of conventional energy sources and the current needs for more efficient and environmental friendly ways to produce, transfer and use energy. For example, renewable energy sources and distributed generation appear to be one of the effective solution for sustainable development and a serious alternative for the protection of environment. In view of the changing nature of energy and power systems, there are critical needs for professionals and engineers that can deal with current and future energy challenges and are able to operate modern power and energy systems. On the other and, the recent changes to the electric power industry through deregulation and restructuring have had considerable effects on power and energy engineering education, both domestically and internationally. In the light of these changes, there is even more imperative need for industry-academia collaboration in the power and energy engineering education. While, the industry benefits by having access to a larger pool of qualified power engineers with practical experiences, the academia can increase the revenue, decrease financial burden on the departments or colleges and can have access to better experimental, research and laboratory infrastructure. Contrary to the misperception and believes by many students, the power and energy industries are introducing advanced and intelligent technologies and equipment, such as: design of advanced and intelligent control systems, system optimization, economic dispatch, open-access transmission systems, advance power electronics equipment, energy economics, renewable energy applications, energy policy issues, advanced communication and monitoring, smart metering, improving system reliability and security, equipment design and protection. The extended power and energy engineering education, minors or certificate programs, online and e-Learning formats are fitting quite well into the conventional academic models that are established at U.S. universities. Additionally, it can be adapted rather easily to fit other electrical engineering sub-disciplines, programs or other engineering areas. The robustness and versatility of this engineering education approach is long overdue and promises to address the engineering manpower concerns already being experienced by U.S. industry. In this paper, we are also discussed our approach to establish and structure a power and energy minor, and any feedback, comments and suggestions from faculty, instructors, educators, researchers and professionals are highly appreciated. It is the authors' strongly believe that such discussions and feedback from other educators, professionals and researchers are improving the program quality, course contents, experiments, laboratory structure or project topics, while in the same time advancing the power and energy engineering education through the introduction of new topics, new or updated laboratory experiments or new applications, as well the development of new course materials, helping the instructors, especially the younger ones interested in education research and teaching in this complex engineering area.

\section{References}

1. NAE, “21 Century's Grand Engineering Challenges”, February 2008, http://national-academies.org (Accessed in October 2018).

2. Energy Independence and Security Act of 2007, available at http://frwebgate.access.gpo.gov/cgibin/ getdoc.cgi?dbname=110_cong_bills\&docid=f:h6enr.txt.pdf; Or, at http://www.oe.energy.gov/smartgrid.htm3

3. M. Kezunovic, V. Vittal, S. Melitopoulos and T. Mount, “The big picture”, IEEE Power Energy Mag. Vol. 10(4), 2012, pp. 22-34.

4. O. Zinaman, M. Miller, A. Adil, D. Arent et al., "Power Systems of the Future”, The Electricity Journal, Vol. 28(2), 2015, pp. 113-126. 
G. T. Heydt, S. S. Venkata, G. A. Gross, and P. W. Sauer, "Promoting the Power Engineering Profession through the IEEE Power Engineering Society”, IEEE Power Engineering Review, January 2000, pp. 17-21.

5. P. Sauer, E. O’Neill, A. Pahwa, B. Malahowski, Y. Makarov, G. Rodriguez, R. Brush, J. Estey, I. Barras, "Model power engineering curriculum for the 21st century", IEEE workshop, St. Louis, MO., May 20-21, 2002.

6. F. C. Berry, P. S. DiPiazza and S. L. Sauer, "The future of electrical and computer engineering education," IEEE Transaction on Education, Vol. 46, no. 4, Nov. 2003, pp. 467-476.

7. P. W. Sauer, G. T. Heydt, and V. Vittal, "The State of Electric Power Engineering Education. IEEE Transactions on Power Systems, Vol. 19, No. 1, February 2004.

8. P. W. Sauer, M. Crow, and M. Venkata, “Manpower Development”, IEEE Power and Energy, Jan./Feb. 2005, pp 30-33.

9. R. Schifo. “Got Power?”, IEEE Power and Energy, Jan./Feb. 2005, p. 48.

10. M. Crow, "Supportive University Relationships Help Companies Find Bright Engineering Graduates," IEEE Power and Energy, Jan./Feb. 2005, pp 34-37.

11. D. Ray, and F. Wayno, "Collaboration to Facilitate Research and Education in a Transitioning Electric Power Industry”, International Energy Journal, Vol. 6(1), Part 4, June 2005, pp 4-151 - 4-164.

12. G. Joós, “Training Future Power Engineers,” IEEE Power and Energy, Jan./Feb. 2005, pp 38-47.

13. G. F. Reed, and D. J. Ray, "IEEE PES Works to Meet Power \& Energy Engineering Education and Workforce Needs: Concerns about the Future Power and Energy Engineering Workforce,” IEEE USA Today's Engineer, July 2008 (online).

14. G.F. Reed, "Two Solutions to Aging Workforce Issues (Pitt Power \& Energy Initiative and KEMA Operations \& Planning Knowledge Tools),” Power Engineering Magazine, Vol. 112, No. 8, August 2008.

15. G. T. Heydt, A. Bose, W. Jewell, M. Kezunovic, J. McCalley, D. Ray, P. Sauer, c. Singh, and V. Vittal, "Professional Resources to Implement the 'Smart Grid'”, presented at the 2009 IEEE PES General Meeting, Calgary, CA, July 26-30, 2009, and at The North American Power Symposium, Mississippi State University, Starkville, MS, October 4-6, 2009.

16. A. Bose, A., Fluek, M., Lauby, et al., "Preparing the U.S. Foundation for Future Electric Energy Systems: A Strong Power and Energy Engineering Workforce,” IEEE Power \& Energy Society, April, 2009.

17. S.C. Bhattacharya, "Renewable energy education at university level”, Renewable Energy, Vol. 22, pp. 91-97, 2001.

18. R.A. Dias, C.R. Mattos, and J.A.P. Balestieri, "Energy education: breaking up the rational energy use barriers", Energy Policy, Vol. 31, pp. 1339-1347, 2004.

19. A. Pahwa, D. M. Grenbacher, S. K. Starrett, and M. M. Morcos, Distance Learning for Power Professionals, IEEE Power and Energy, Jan./Feb. 2005, pp 53-66.

20. P.K. Sen, Designing the First Entry-Level Course in Power Systems Engineering: To Best Meet the Industry Needs, 2007 Power Engineering Society General Meeting, Tampa Bay, Florida, June 24-29, 2007, DOI:10.1109/PES.2007.385576

21. R. E. Fehr, A Model Curriculum for Power Engineering, 2008 IEEE Power Engineering, pp.1-5.

22. P. Jennings, "New directions in renewable energy education”, Renewable Energy, vol. 34, pp. 435-439, 2009.

23. T. Aboumahboub, K. Schaber, P. Tzscheutschler, T. Hamacher, "Optimal configuration of a renewable-based electricity supply sector”, WSEAS Transactions on Power Systems, Vol. 5, 2010, pp. 120-129.

24. B. Russel, "Educating the workforce for the modern electric power systems university-industry collaboration", Bridge Electricity Grid, Vol. 40(1), 2010, pp. 35-41.

25. N. Mohan, "New initiatives in power engineering education at the University of Minnesota," in Power and Energy Society General Meeting, 2011 IEEE, July 2011, pp. 1-2.

26. C. Singh, "Workforce development for the future grid to enable sustainable energy systems," in Power and Energy Society General Meeting, 2012 IEEE, July 2012, pp. 1-2.

27. B. Chowdhury, B. Parkhideh, A. Martin, Z. Salami, J. Enslin, V. Cecchi, S. Kamalasadan, and N. Maciej, "Enhancing power and energy systems concepts with laboratory experience," in Power and Energy Society General Meeting (PES), 2013 IEEE, July 2013, pp. 1-5. 
28. G. Reed and W. Stanchina, "Smart grid education models for modern electric power system engineering curriculum," in Power and Energy Society General Meeting, 2010 IEEE, July 2010, pp. 1-5.

29. M. Ilic, "Teaching smart grids: Yet another challenge and opportunity for transforming power systems curriculum,” in Power and Energy Society General Meeting, 2010 IEEE, July 2010, pp. 1-2.

30. M. Kezunovic, "Teaching the smart grid fundamentals using modeling, simulation, and hands-on laboratory experiments”, in Power and Energy Society General Meeting, 2010 IEEE, July 2010, pp. 1-6.

31. N. N. Schulz, "Integrating Smart Grid Technologies into an Electrical and Computer Engineering Curriculum, Innovative Smart Grid Technologies”,2011 ASIA (ISGT), IEEE PES, 2011, pp. 1-5.

32. R. Belu and I. Husanu, "An Undergraduate Course on Renewable Energy Conversion Systems for Engineering Technology Students”, 2011 ASEEE Conference \& Exp., June 26 - 29, Vancouver, BC, Canada (CD Proc.).

33. N. Hosseinzadeh, and M. R. Hesamzadeh, "Application of Project-Based Learning (PBL) to the Teaching of Electrical Power Systems Engineering”, IEEE Trans. Educ., Vol. 55 (4), 2012, pp. 495-501.

34. M. Shahidehpour, "Smart grid education and workforce training center," in Innovative Smart Grid Technologies Asia (ISGT), 2011 IEEE PES, Nov 2011, pp. 1-3.

35. K. Schaber, F. Steinke, and T. Hamacher, "Transmission grid extensions for the integration of variable renewable energies in Europe: Who benefits where?”, Energy Policy, Vol. 43, 2012, pp. 123 - 135, doi: 10.1016/j.enpol.2011.12.040.

36. R. Belu, "Power Electronics and Controls for Photovoltaic Systems", in Handbook of Research on Solar Energy Systems and Technologies (Eds: Dr. Sohail Anwar, Dr. Salahuddin Qazi, and Dr. Harry Efstathiadis), IGI, Global, pp. 68-125, 2012 (DOI: 10.4018/978-1-4666-1996-8.ch004).

37. F. J. Lozano and R., Lozano, “Developing the curriculum for a new Bachelor's degree in Engineering for Sustainable Development”, Journal of Cleaner Production, Vol. 64, 2014, pp. 136-146.

38. J. Viola, J. Restrepo, F. Quizhpi, M. I. Gimenez, J. Aller, V. Guzman, and A. Bueno, “A Flexible Hardware Platform for Applications in Power Electronics Research and Education”, 2014 IEEE Electr. Power Energy Conference, 2014, pp. 226-232.

39. D. S. Ochs, Member, and R. Douglas, "Teaching Sustainable Energy and Power Electronics to Engineering Students in a Laboratory Environment Using Industry-Standard Tools”, IEEE Transactions on Education, Vol. 58(3), 2015, pp. 173-178.

40. H. Malkki, K. Alanne, and L. Hirsto, "A method to quantify the integration of renewable energy and sustainability in energy degree programmes: a Finnish case study”, Journal of Cleaner Production, Vol.106, 2015, pp. 239 - 246.

41. R. G. Hardgraft, "New curricula in engineering education: experience, engagement, e-resources”, Global J. of Eng. Educ. Vol. 19(2), 2017, pp. 112-117.

42. G. Chicco, P. Crossley, and C. A. Nucci, "Electric Power Engineering Education: Cultivating the Talent in the United Kingdom and Italy to Build the Low-Carbon Economy of the Future”, Vol. 16(5), 2018, pp. 53-63.

43. M. Parvania and H. M. Merrill, "Toward a 21st Century Power Education: A Bright Future Awaits Students in Utah”, IEEE Power and Energy Magazine, Vol. 16(5), 2018, pp. 87 - 95.

44. R. Belu, Industrial Power Distribution, Embedded and Distributed Generation, IET Press, 2018

45. R. Belu, Renewable Energy Systems: Fundamentals and Source Characteristics, Taylor and Francis, CRC Press, 2019.

46. R. Belu, Renewable Energy Systems: Energy Storage, Grind Integration, Energy Economics and the Environment, Taylor and Francis, CRC Press, 2019.

47. R. Belu, Building Electric Systems and Distribution Networks, Taylor and Francis, CRC Press, 2020.

48. R. Belu, Fundamentals of Smart Grids, Taylor and Francis, CRC Press, 2020 (in print). 